\title{
Research on Informationization Construction of Scientific Research Management in Colleges and Universities Under Big Data Environment
}

\author{
Li LIN \\ Science and Technology Department, Shanghai Sanda University, Shanghai, China
}

Keywords: Informationization; College and University; Scientific Research Managemenet; Big Data.

\begin{abstract}
With the rapid development of information age, the informationization construction in colleges and universities is also in full swing. Introducing big data into colleges and universities scientific research management can simplify the work flow and provide sufficient resources and also can provide certain decision-making consultation and guidance. This paper analyzes the existing problems in the scientific research management system of colleges and universities under the big data environment, lists some thoughts on the scientific research management under the big data environment, and finally puts forward the construction scheme of scientific research management informatization under the big data environment.
\end{abstract}

\section{Introduction}

With the rapid development of information age, the informationization construction in colleges and universities is also in full swing. Many colleges and universities are developing specialized databases and data systems. Due to the complexity of data management and the large number of processes, it needs a large number of manpower and material resources to support, which brings tremendous pressure to the scientific and technological departments of colleges and universities. It is not only extremely inefficient, but also difficult to ensure the quality of work.

In this case, the introduction of big data technology into the scientific research management of colleges and universities to promote the informatization of scientific research management can not only simplify the work process, but also reduce the workload. It can also provide sufficient resources for the scientific research management of colleges and universities and provide certain decision-making consultation and guidance. However, considering the informatization of scientific research management universities at present, there are still many problems to be solved due to the influence of talent reserve and technology.

\section{The Existing Problems in the Scientific Research Management System of Colleges and} Universities under the Big Data Environment

\subsection{The Construction of Scientific Research Management System is not Perfect}

Some colleges and universities have not established the scientific research information platform and the network management system which adapts to the development. The lack of corresponding software and database, unreasonable combination and utilization of resources, and unreasonable decision-making in scientific research management are all unfavorable factors for the lag of the development of scientific research management system in colleges and universities.

\subsection{The Coordination of Scientific Research Management System is not Perfect}

Different school departments have established different management systems. Financial department has a special financial management system; personnel department has human resource management system; scientific research has scientific research management system. Some of the data in these systems are related. Both human resource management system and scientific research management system have basic personnel information; both financial management system and scientific research management system have information related to project fund management. As a 
result, the data of each system is not coordinated enough when updated and maintained, and the same data is inconsistent. This also limits the exchange and sharing of data resources.

\subsection{The Data Analysis of Scientific Research Management System is not Perfect}

In recent years, some colleges and universities have been investing more and more in informatization construction of scientific research management. However, due to the lack of guidance of scientific theories and sufficient technical support, scientific research management still remains in the stage of data collection. In general, the system conducts statistics and management of scientific research projects, input of results and simple inquiry. With the accumulation of time, the scientific research management department has accumulated a lot of scientific research data resources. Due to the lack of data analysis and data mining, the deep value of the data cannot be embodied, which cannot provide scientific and effective reference basis for the decision-making of scientific research management in colleges and universities.

\section{Some Thoughts on the Scientific Research Management under the Big Data Environment}

Scientific research management standardization is the foundation of scientific research work, and also the foundation of scientific research management information system construction in the era of big data. There are mainly the following contents:

\subsection{Scientific Research Process Management}

From the implementation of scientific research to the identification of results, large data technology can be used to manage the whole process of scientific research projects, so as to achieve the overall supervision of project progress, project planning, human resource management, financial supervision and other links. The emphasis is on the implementation of process management. Project approval management is mainly about the declaration, mobilization, organization, guidance and assistance. The implementation process is to do a good job in the opening, daily supervision, mid-term inspection, funds allocation and review, the conclusion of the organization and guidance, subject acceptance and appraisal, submitted to the examination and approval, filing and other work.

\subsection{Management of Scientific Research Achievements}

Scientific evaluation of scientific research achievements should establish an objective, impartial and efficient scientific research evaluation system, establish and improve an efficient scientific research evaluation and supervision mechanism, establish a peer expert evaluation system within the school, introduce peer experts outside the school to evaluate, and implement quantitative and qualitative combination to improve the accuracy and authority of scientific research achievements evaluation. The registration of scientific research achievements is an important part of the management of scientific research achievements.

\subsection{Academic Activity Management}

Academic activity management is to organize, undertake or participate in academic exchanges, including various forms of academic conferences, special argumentation and discussion, lectures by famous scholars at home and abroad, special lectures, etc. Establish management methods and procedures.

\subsection{Intellectual Property Management}

Establish an organization system suitable for the management and protection of intellectual property in colleges and universities. Standardizing the process of school intellectual property management, mobilizing the enthusiasm of all teachers, students and employees to take the initiative and actively engage in intellectual innovation activities, and producing more independent intellectual property with core competitiveness. We should guide and organize the implementation of the management model to prevent intellectual property losses, avoid disputes, improve the quantity and quality of independent intellectual property, enhance the capacity for independent 
innovation, and promote the transformation of achievements and the use of knowledge.

\subsection{Evaluation and Management of Scientific Research Projects}

Along with the informatization level unceasing enhancement, it makes the data information scale unceasingly expands. In this case, how to obtain the information needed in the massive data becomes the key problem. If the traditional data analysis and statistical methods are used, not only a lot of manpower and material resources are needed, but also the work efficiency and quality are difficult to be guaranteed. Big data technology can accurately identify and classify the specific data of university scientific research projects according to the internal and external data of the system, and search out the data resources that can be used in scientific research projects from the massive information.

\subsection{Decision-Making Management of Scientific Research Projects}

Through big data technology, the scientific and innovative nature of the subject can be combined with the external document database for analysis. Secondly, the factors involved in the applicant shall conduct joint query and analysis of multiple data, discover and establish a scientific indicator system and project screening method, exclude unreasonable factors before the project is set up, and reasonably select the project to be funded.

\subsection{Scientific Research Resource Allocation Management}

The allocation mode of scientific research resources based on big data technology can be divided into three levels. First, data collection and cleaning, and the establishment of scientific research resource database including personnel database, fruit database, fund database and scientific research resource database based on scientific research room and scientific research instrument. The second part is to establish the evaluation model library suitable for the development of each university, including the calculation parameters and rules database of various scientific research resources and achievements. Finally, the resource allocation tool and decision support management tool based on quantitative performance assessment are used to complete the optimization allocation process of scientific research resources based on big data technology.

\section{Construction Scheme of Scientific Research Management Informatization under the Big Data Environment}

The construction of scientific research management informatization under the big data environment can be considered from four aspects: data source, data warehouse, data analysis and data application. Figure 1 is the flow chart of scientific research data analysis under the big data environment.

In big data environment, the amount of data is huge. For scientific research management, data sources can come from three aspects: internal, external and Web. Internal data can obtain data information about personnel, projects, funds, equipment, etc. External data can obtain information about the number, category and topic of corresponding research projects from the competent research department. The web can obtain information such as papers, intellectual property (patents, software copyright), and so on.

Scientific research data warehouse collects all kinds of internal, external and web data, which is the data base of scientific research data analysis and management. Scientific research data warehouse can directly carry out basic query and statistics in project management and generate various reports.

The data analysis stage is the key of scientific research data management. It is the basic stage of data collation and analysis, which can be carried out by means of existing artificial intelligence, data mining and data analysis.

In the data application stage, the evaluation and decision-making of scientific research data are mainly completed. The main aspects involved include scientific research planning, scientific research assessment, project management and evaluation, and scientific research resource 
optimization.

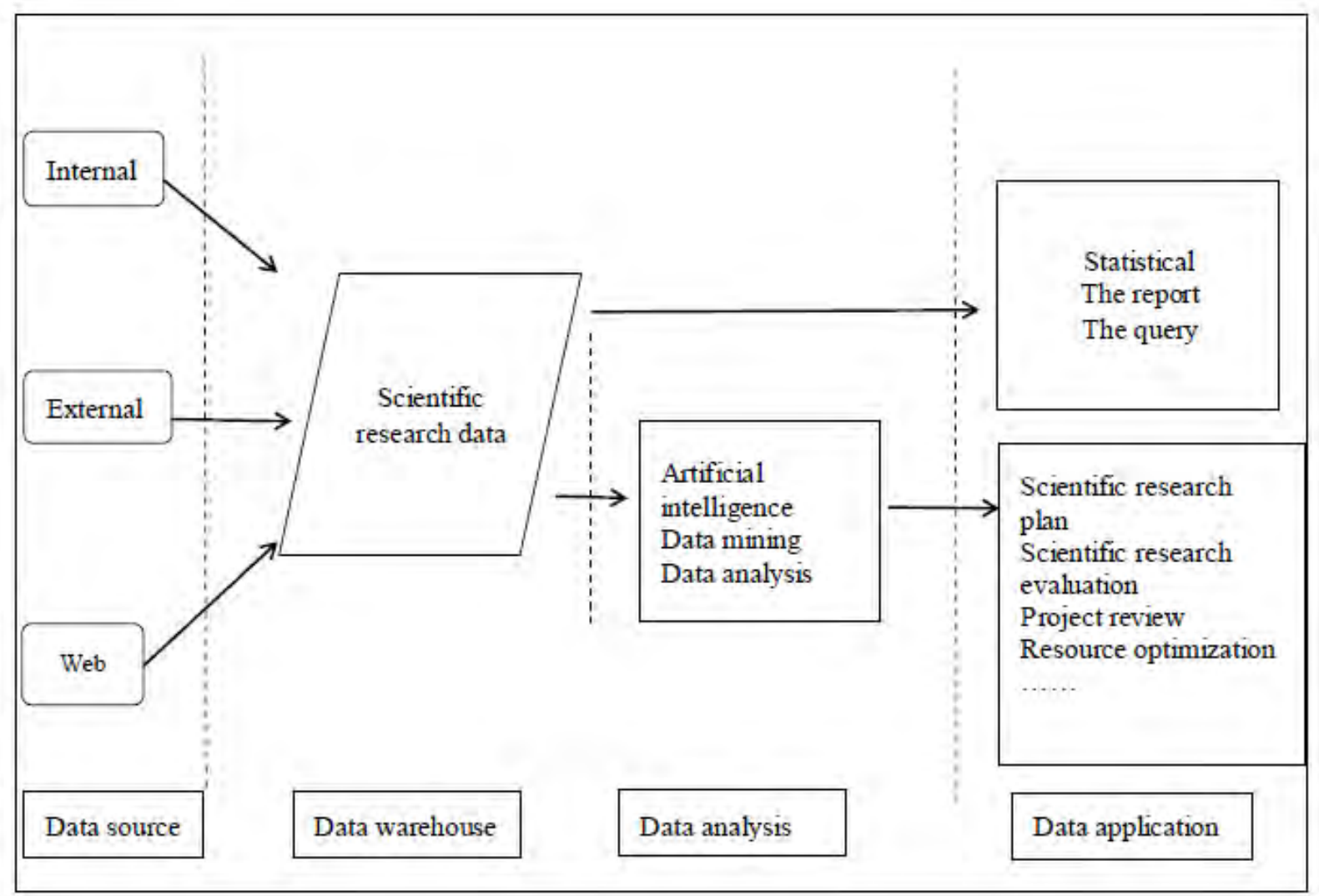

Figure 1. Scientific Research Data Analysis under the Big Data Environment

Based on the flow chart of scientific research data analysis under the big data environment, we constructed the construction scheme of scientific research management informatization under the big data environment. As shown in figure 2.

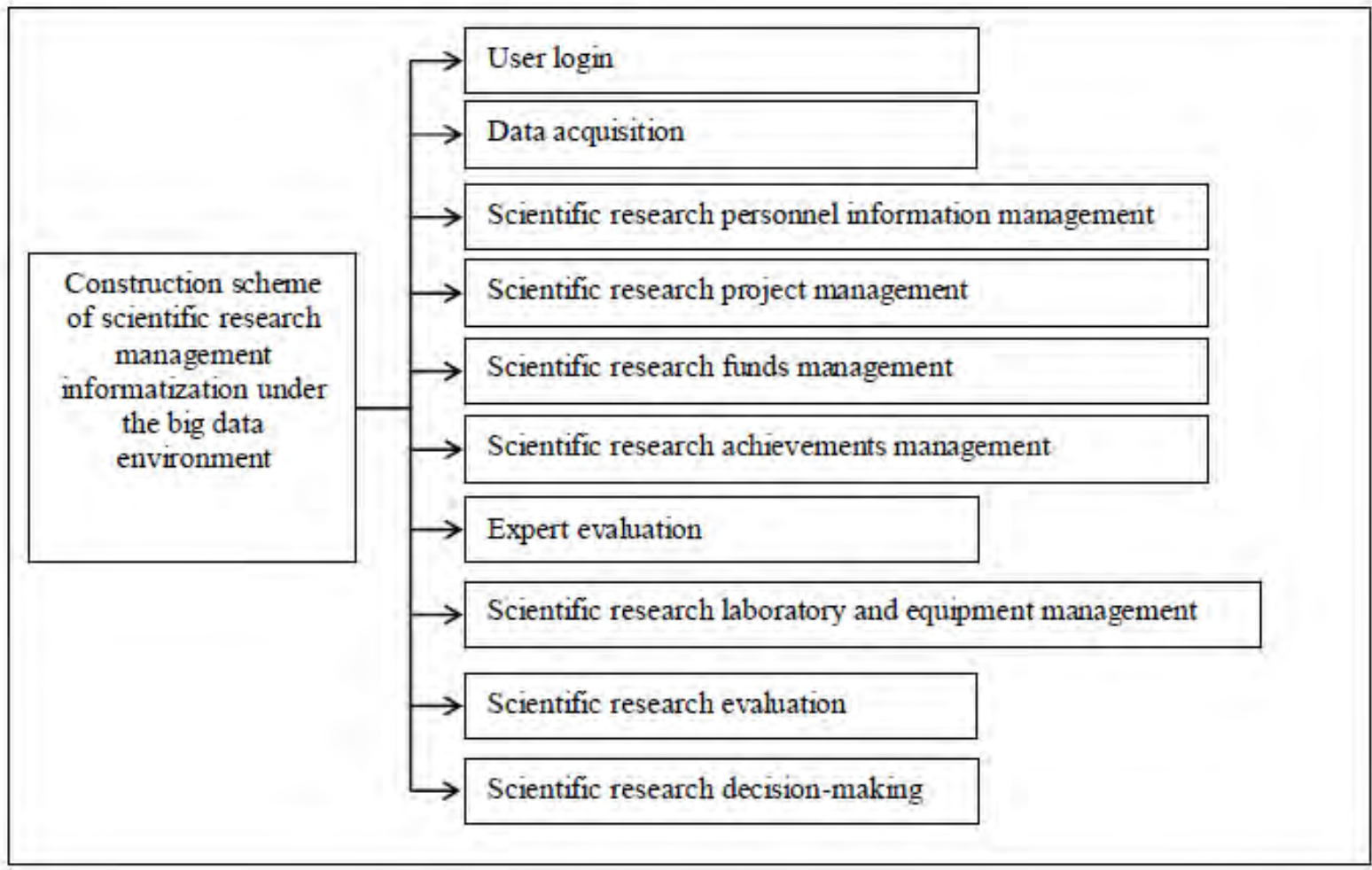

Figure 2. Construction Scheme of Scientific Research Management Informatization under the Big Data Environment 


\subsection{User Login}

This section considers the login of people of different roles. It includes scientific research managers, research project managers, scientific researchers, financial managers, human resource managers and system administrators.

\subsection{Data Acquisition}

To form data warehouse, we need to get certain data. It mainly obtains data from external and web sources, including scientific research projects and categories, intellectual property projects.

\subsection{Scientific Research Personnel Information Management}

This part needs the intervention of human resource managers to improve the information of scientific researchers, mainly including basic information of scientific researchers, research direction of scientific researchers and so on. The basic information of scientific research personnel needs to be connected with the human resource management system to ensure the accuracy and consistency of the information.

\subsection{Scientific Research Project Management}

Scientific research project management includes project declaration management, project approval management, process management and conclusion management. This is an important part of project management. The declaration of the project is mainly completed by the project leader. The project management shall be completed by scientific research management personnel and financial management personnel, and the financial management personnel shall set fund details after the project is approved. The project process management and project conclusion management are jointly completed by the project leader and scientific research management personnel. The scientific research management personnel set the process and project conclusion time nodes, and the scientific research management personnel submit corresponding materials.

\subsection{Scientific Research Funds Management}

This part needs the intervention of financial management personnel to complete the management of scientific research project funds. This includes the allocation of funds, approval of the use of funds, etc. This data needs to be linked to the financial system to ensure the consistency of research funding data.

\subsection{Scientific Research Achievements Management}

The management of scientific research achievements mainly includes research awards, published papers, monographs, translations and intellectual property management. The scientific research results shall be input by the scientific research personnel or the project leader, and the scientific research management personnel shall review and complete the information.

\subsection{Expert Evaluation}

Scientific research managers will determine the basis of expert team composition according to the type of project and other relevant attributes, such as the number of technical experts, the number of financial experts, etc. After the experts received the review notice, they completed the project review online, and the results were finally shown to the scientific research management.

\subsection{Scientific Research Laboratory and Equipment Management}

Scientific research laboratory information input, corresponding equipment and use management.

\subsection{Scientific Research Evaluation}

On the basis of data warehouse, various data such as projects, papers, intellectual property rights, achievements and awards are analyzed, and a comprehensive evaluation model is established to integrate various indicators to provide data support for research evaluation experts or school leaders. 


\section{Summary}

Scientific research decision includes scientific research project approval decision and scientific research plan decision. The decision of scientific research project approval is based on data warehouse. Under the reasonable index system and selection conditions, the project to be declared or funded is reasonably selected. Scientific research planning and decision-making should be determined according to the development direction and background of various disciplines in the overall environment, so as to provide certain decision-making consultation for the overall development and planning of the school.

\section{References}

[1] Xu Zhijun, fu yao. Exploration of informatization of university scientific research management under the big data environment [J]. Technology and innovation management, 2014, 35 (2): 112-115.

[2] Guan Yingchao, Chen LAN, xu shibin. Innovation discussion of university scientific research management under new circumstances [J]. Journal of sichuan normal university, 2010.7 (33).

[3] http://www.sohu.com/a/227095585_414933 big data environment of university scientific research management information 